\title{
Management of a Giant Cystic Mass in a Young Otherwise Healthy Woman
}

\author{
Ann C. Gaffey, MD; Steven E. Raper, MD, JD* \\ Hospital of the University of Pennsylvania and the Department of Surgery, Perelman School of Medicine, \\ University of Pennsylvania, Philadelphia, USA
}

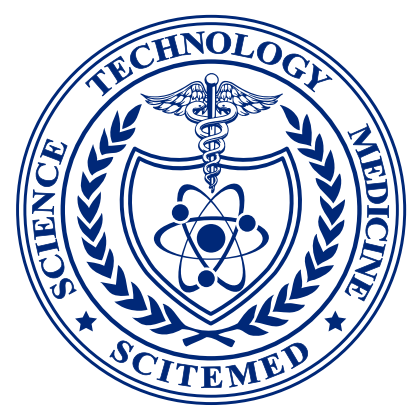

\begin{abstract}
We report a new perspective on the case of a 22-year-old female with no significant medical history who posed a diagnostic and therapeutic challenge; a giant cystic mass of the abdominal cavity. Work up was notable for no significant laboratory abnormalities but a large cystic lesion noted on imaging. The patient underwent open resection. A giant cystic abdominal tumor may present with the common and protean abdominal symptoms of bloating, pain, and early satiety from either mass effect or adhesions to surrounding structures. Caution is advised in attempting the laparoscopic resection of such tumors.
\end{abstract}

\section{Case Report}

A 22-year-old female student presented with pain, early satiety, a dragging sensation in the abdomen, and weight gain. She had been diagnosed with irritable bowel syndrome several years prior based on the symptoms. Over the preceding 6 months, she reported increasing frequency of progressive nausea primarily with meals, emesis nearly every day, and constipation. She noted early satiety but no evidence of dysphagia or odynophagia. Overall, she had a 20-pound weight gain within 4 months prior to diagnosis. The patient had no significant past medical or surgical history. Within her family history, there was no history of ovarian disease, gastrointestinal malignancies, or cystic disease. She reported regular menstrual cycle with an age of menarche of 12 . A pregnancy test at admission was negative. Prior to diagnosis she had taken to wearing exclusively yoga pants because belts were uncomfortable.

Physical examination was notable for diffuse abdominal distention and a fluid wave without peritonitis or evidence of a hernia. Percussion was dull throughout. A CT scan of the abdomen and pelvis noted a large cystic mass with internal attenuation, occupying the majority of the abdomen with mass effect resulting in superior displacement of the liver, spleen, stomach, as well as the majority of the small bowel located in the left side of the abdomen (Figure 1). Tumor marker studies, including beta-HCG, CA 19-9, carcinoembryonic antigen, and CA125 were negative.

After discussion of options including a laparoscopic approach, and the small but real risk of a cancer diagnosis, an open approach was judged best to avoid rupture of the cyst. The patient was taken to the operating room for an exploratory laparotomy. A 40-cm cyst arising from the right ovary was noted (Figure 2) and on full inspection of the abdomen there was a normal appearing uterus, normal left ovary and fallopian tube, normal pelvis and paraaortic lymph nodes, normal peritoneum, and normal bowel. Gynecologists, having obtained prior consent, performed a right oophorectomy and salpingectomy in continuity with the mass. She recovered rapidly with normal dietary intake. The final pathology of the $10.4 \mathrm{~kg}$ cyst was serous cystadenofibroma and ovary with hemorrhagic corpus luteum.

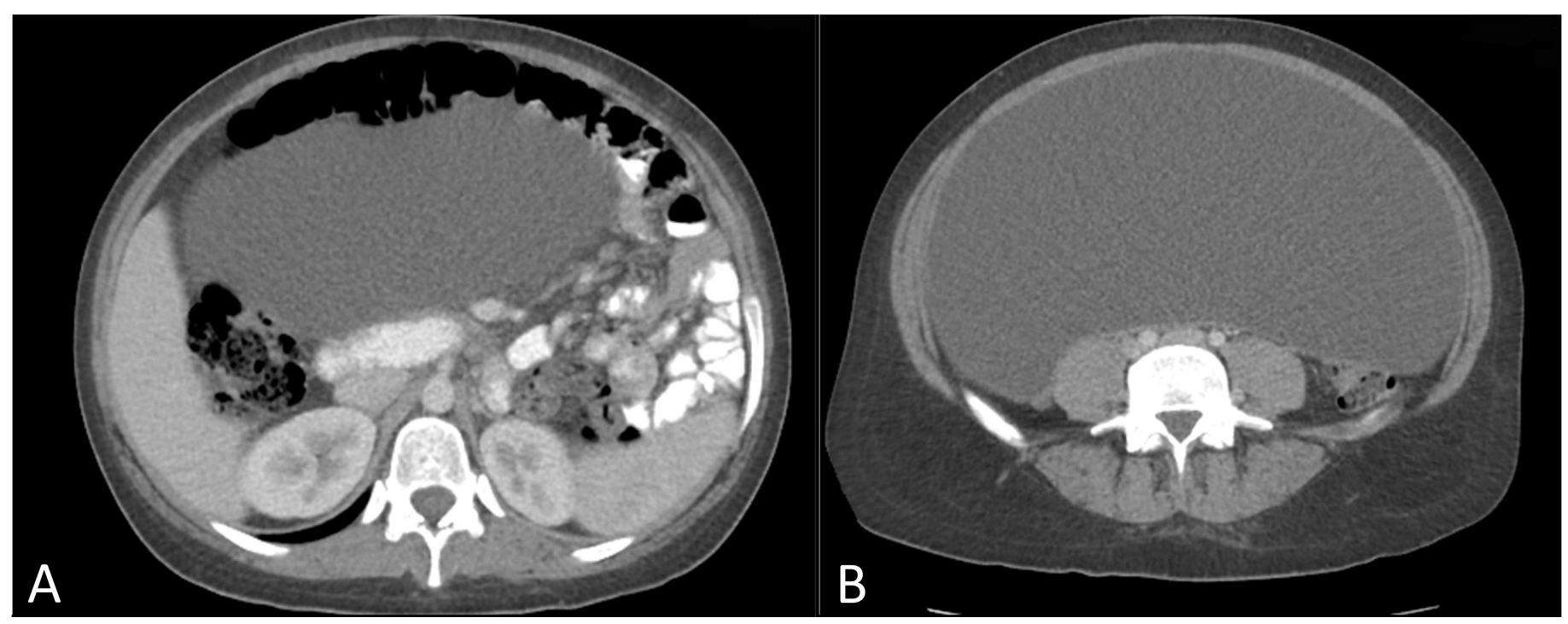

Figure 1. Cephalad axial image noting compression of small bowel to the left side of the abdomen (A). Further distal axial image in which the cyst is occupying the majority of the intra-abdominal cavity (B). 

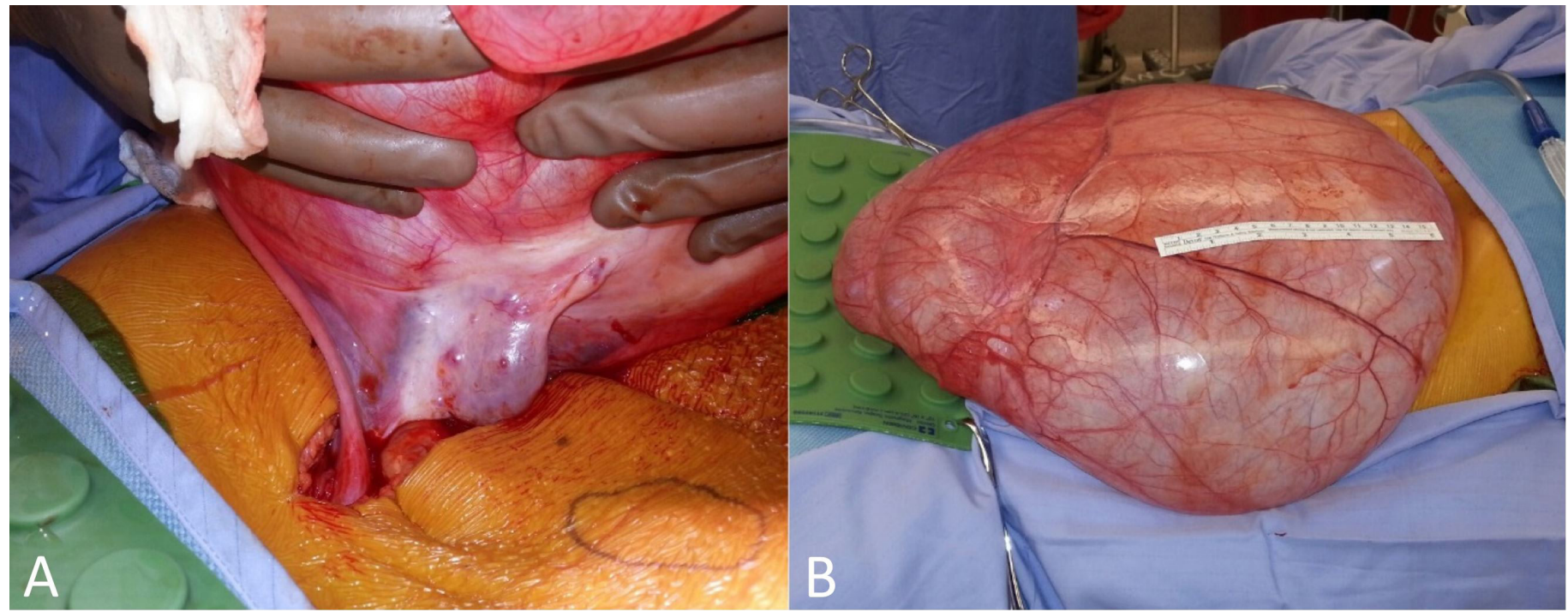

Figure 2. Intra-operative Images. Right ovary with noted cyst (A) and unruptured cyst (B). The length of the ruler in panel B is $15 \mathrm{~cm}$.

\section{Discussion}

Slow, insidious, growth of the cystic mass in an otherwise young healthy woman obscured the diagnosis; presumably for several years. The differential diagnosis of diffuse, low grade abdominal pain, bloating and even weight gain is broad. However, the development of early satiety suggests the need for a more thorough evaluation. Once ordered, computed tomography rapidly established the presence of an abdominal cystic mass. Ultrasound or magnetic resonance imaging could also have pointed toward the correct diagnosis. The list of cystic masses of the abdominal cavity is long (Table 1). Size is a major determinant of the clinical diagnosis of such masses; although most adnexal cystic masses are benign, the possibility of malignancy mandates the need for accurate diagnosis and treatment [1,2]. Most authors have suggested that adnexal cysts that are unilocular, unilateral and less than $5 \mathrm{~cm}$ are benign [3].

As highlighted by the current case, it is essential to consider gynecologic conditions in the differential diagnosis of cystic abdominal masses in women. Although ovarian cysts over $10 \mathrm{~kg}$ are rare with the advent of modern health care imaging, the most common etiology of benign tumors - cystic and otherwise - includes mature teratomas, fibromas, serous cystadenomas, mucinous cystadenomas, and Brenner tumors [4,5]. Ovarian serous cystadenofibromas as described here are characterized by a prominent fibrous tissue component in addition to the epithelial elements [6]. Despite the tumor size, histologically these cysts are benign and account for about $1.7 \%$ of all benign ovarian tumors [7].

Correct determination of the histology must inform treatment. There is an emerging literature for the laparoscopic removal of abdominal cystic masses, adnexal and otherwise [8]. However, caution is advised in the laparoscopic removal of abdominal cystic lesions, even if technically feasible [9]. In a series of sixteen laparoscopically removed mesenteric cysts, $25 \%$ had malignant components (three cystadenocarcinoma, one leiomyosarcoma) [10]. In these cases, one had intraperitoneal spill and two had 'questionable resection margins' with no longterm follow up [8].

The concern about malignancy also arises in laparoscopic removal of ovarian cysts. A series of 77 laparoscopically removed cysts showed evidence of borderline histopathology in $3.7 \%$ and invasive cancer in $2.5 \%$ [11]. In the present case, although the patient's age, tumor marker profile and the radiologic characteristics suggested the tumor was probably benign, it was judged safest to remove the tumor in a non-ruptured state through a conservative laparotomy incision to avoid any possibility of seeding a cancer throughout the peritoneal cavity.

\section{Conclusion}

For patients with vague yet common and protean abdominal symptoms, a giant cystic abdominal tumor should be included within the differential diagnosis. A through history and physical examination are necessary to discern any emergent need for intervention. Ultimate diagnosis is determined through imaging. When planning an operative intervention, caution is advised in attempting the laparoscopic resection of such tumors.

\begin{tabular}{l} 
Table 1. Differential Diagnosis of Intra-abdominal Cystic Masses \\
\hline Benign Non-Adnexal Cystic Masses \\
\hline Anterior Spinal Cyst \\
\hline Cystic Teratoma \\
\hline Enteric Duplication Cysts \\
\hline Lymphangioma \\
\hline Lymphocele \\
\hline Mesenteric Cysts \\
\hline Mucocele of the Appendix \\
\hline Peritoneal Inclusion Cyst \\
\hline Pseudocysts \\
\hline \multicolumn{1}{|c|}{ Inflammatory } \\
\hline Traumatic \\
\hline Benign Adnexal Non-Ovarian Cystic Masses \\
\hline Cystic Degeneration of Exophytic Fibroid \\
\hline Endometriomas \\
\hline Hydrosalpinx \\
\hline Paraovarian Cyst \\
\hline Tubo-Ovarian Abscess \\
\hline Benign Ovarian Cystic Masses \\
\hline Corpus Luteal Cyst \\
\hline Ovarian Hyperstimulation Syndrome \\
\hline Theca Luteal Cyst \\
\hline Malignant Cystic Masses \\
\hline Gastrointestinal Stromal Tumor \\
\hline Leiomyosarcoma \\
\hline Mucinous Cystadenocarcinoma \\
\hline Ovarian Cancer \\
\hline
\end{tabular}




\section{CASE REPORT}

\section{Article Information}

*Correspondence: Steven E. Raper, MD, JD

Hospital of the University of Pennsylvania and the Department of Surgery, Perelman School of Medicine, University of Pennsylvania, Philadelphia, USA. Email: rapers@uphs.upenn.edu

Received: Nov. 14, 2017; Accepted: Dec. 06, 2017; Published: Feb. 09, 2018

DOI: $10.24983 /$ scitemed.acri.2018.00052

Copyright (c) 2018 The Author(s). This is an open-access article distributed under the terms of the Creative Commons Attribution 4.0 International License (CC-BY).

\section{Funding: None}

\section{Conflict of Interest Disclosures: None}

\section{Keywords}

Abdominal cavity; adnexa; giant cystic mass; open vs. laparoscopic resection.

\section{References}

1. Boyle KJ, Torrealday S, Benign gynecologic conditions. Surgical Clinics of North America 2008;88:245-264.

2. Katke RD. Giant mucinous cystadenocarcinoma of ovary: a case re- port and review of literature. Journal of Mid-life Health 2016;7:41-44.

3. Buluş $H$, Akkoca $M$, Coskun A, Koçak E, Köklü $S$. Benign ovarian cyst presenting as a huge intrabdominal mass in an elderly postmenopausal woman. Journal of the American Geriatric Association 2012;60:1170-1172.

4. Abe T, Iwaoki Y, Tanji H, Kodama S, Shigeta N, Sumimoto K. Resection of a giant ovarian mucinous cystadenoma with intraoperative drainage. Journal of Gynecologic Surgery 2012;28:215-219.

5. Einenkel J, Alexander H, Schotte D, Stumpp P, Horn LC. Giant ovarian cysts: is a pre- and intraoperative drainage an advisable procedure? International Journal of Gynecologic Cancer 2006;16:2039-2043.

6. Czernobilsky B, Borenstein R, Lancet M. Cystadenofibroma of the ovary: a clinicopathologic study of 34 cases and comparison with serous cystadenoma. Cancer 1974;34:1971-1981.

7. Cho SM, Byun JY, Rha SE, et al. CT and MRI findings of cystadenofibromas of the ovary. European Radiology 2004;14:798-804.

8. Bhandarwar AH, Tayade MB, Borisa AD, Kasat GV. Laparoscopic excision of mesenteric cyst of sigmoid colon. Journal of Minimal Access Surgery 2013;9:37-39.

9. Uyanikoglu $H$, Dusak A. A huge ovarian dermoid cyst: successful laparoscopic total excision. Journal of Clinical and Diagnostic Research 2017;11:QD03-QD05.

10. Tan J, Tan KK, Chew SP. Mesenteric cysts: an institution experience over 14 years and review of literature. World Journal of Surgery 2009;33:1961-1965.

11. Lim S, Lee KB, Chon SJ, Park CY. Is tumor size the limiting factor in a laparoscopic management for large ovarian cysts? Archives of Gynecology and Obstetrics 2012;286:1227-1232. 